\title{
Direct Somatic Embryogenesis: A Highly Efficient Protocol for In Vitro Regeneration of Habanero Pepper (Capsicum chinense Jacq.)
}

\author{
Guadalupe López-Puc, Adriana Canto-Flick, Felipe Barredo-Pool,
} Patricia Zapata-Castillo, María del C. Montalvo-Peniche, Felipe Barahona-Pérez, and Nancy Santana-Buzzy ${ }^{1}$

Unidad de Bioquímica y Biología Molecular de Plantas, Centro de Investigación Cientifica de Yucatán, Calle 43 \#130, Chuburná de Hidalgo, Mérida, Yucatán, 97200, México

\section{Lourdes Iglesias-Andreu \\ Laboratorio de Biotecnología y Ecología Aplicada, Universidad Veracruzana, Campus para la Cultura, las Artes y el Deporte, Av. de las Culturas Veracruzanas No. 101, Colonia Emiliano Zapata, CP.91090, Jalapa, Veracruz, México}

Additional index words. Capsicum chinense, habanero pepper, direct somatic embryogenesis

\begin{abstract}
To induce somatic embryogenesis in habanero pepper (Capsicum chinense Jacq.), the cultivar BVII-03, belonging to the red type, was used. Different explants were evaluated, as were different culture media, the composition of which varied in the content of plant growth regulators. Results showed the formation of somatic embryos from cotyledons, zygotic embryos, germinated zygotic embryos, hypocotyls, and cotyledonary leaves. Explants were cultured on Murashige and Skoog medium supplemented with 2,4-D $(9.05 \mu \mathrm{M})$. The somatic embryos always formed directly from the explant, without callus formation, and the greatest efficiency was obtained when segments of hypocotyls were cultured, obtaining $175 \pm 20$ somatic embryos per explant. Only the somatic embryos obtained on Murashige and Skoog medium containing 2,4-D (9.05 $\mu \mathrm{M})$ and treated with abscisic acid (ABA) $(1.89 \mu \mathrm{M})$ before their transfer to the germination media (Murashige and Skoog $+1.1 \mu M \mathbf{G A}_{3}$ ) emitted their radicule and expanded their cotyledonary leaves $(60 \%)$, whereas the remaining embryos did not achieve germination because of different causes (abnormalities, delayed development). Not only is this protocol of somatic embryogenesis the first to be reported for this species $(C$. chinense Jacq.), but it is also the most efficient reported so far, within the Capsicum genus.
\end{abstract}

All chili peppers belong to the Capsicum genus of the Solanaceae family. There are 27 species of Capsicum, but only five of these have been domesticated and cultivated: $C$. annuum Linné, C. baccatum Linné, C. chinense Jacquin, C. frutescens Linné, and $C$. pubescens Ruiz \& Pavón. Capsicum chinense or Habanero pepper, as it is known in México and other parts of the world, differs from the rest of the peppers in the higher level of pungency in the fruit, which is recognized as the hottest (the most spicy) known (DeWitt and Bosland, 1993). Although the point of origin of $C$. chinense is located in the Amazon (Greenleaf, 1986), the Yucatán Peninsula, in Mexico, is considered to be

Received for publication 17 May 2006. Accepted for publication 15 July 2006 .

We would like to thank the Fundación Produce Yucatán and the SINAREFI for the funding of this study. Our thanks also to Guadalupe Dzib Amaro for her support throughout this work.

${ }^{1}$ To whom reprint requests should be addressed; e-mail buzzy@cicy.mx been obtained, and the majority of these have been from immature or mature zygotic embryos. The only report of somatic embryogenesis in the genus, using leaf explants, was carried out quite recently by Kintzios et al. (2001).

To date, there are two reports of plant regeneration in habanero pepper via organogenesis (Santana-Buzzy et al., 2005, 2006), in which the inhibition of the effects of ethylene was also studied. Somatic embryogenesis has not previously been described in C. chinense Jacq. This is the first report of a protocol of regeneration via direct somatic embryogenesis from Capsicum chinense Jacq. It is convenient to obtain somatic embryos that develop directly from the explants, because there is a greater tendency for them to be genetically more uniform than the embryos generated from the callus (Maheswaran and Williams, 1984).

Conventional breeding is a long process with problems of interspecific incompatibility on many occasions. Somatic embryogenesis can offer efficient solutions to these problems, particularly when there is a need to recover and propagate plants in large numbers from genetically transformed plant cells (Buyukalaca and Mavituna, 1996). Habanero pepper has much demand on an international scale, because it has multiple uses. Nevertheless, the diseases and the lack of efficient strategies to obtain improved cultivars have made it impossible to cover its demand from the different industries that require the product. The aim of this study was to establish a protocol of somatic embryogenesis, as a basic tool for the genetic transformation of plants, and to incorporate it in our strategy for the use and efficient management of a collection of this species (C. chinense Jacq.) that is being conserved and characterized in our laboratory.

\section{Materials and Methods}

the center of genetic diversity for this species given the great variety of shapes, size, color, taste, aroma, and pungency of its cultivars. Besides being consumed fresh and processed, because of its high capsaicin content, it is also the raw material for the elaboration of medicines, spray repellent, anticorrosives, cosmetics, and shampoo.

Although cell culture and plant regeneration have been achieved in many members of the Solanaceae family, Capsicum is still considered to be a genus recalcitrant to in vitro morphogenesis. Most of the regeneration methods reported for Capsicum annuum L. involve direct organogenesis from cotyledons and hypocotyls. The major problem in the process of in vitro regeneration is shoot elongation, which occurs more often in hot pepper and in $C$. frutescens than sweet pepper varieties (Franck-Duchenne et al., 1998). There are very few reports of somatic embryogenesis in C. annuum (Binzel et al., 1996; Buyukalaca and Mavituna, 1996; Harini and Sita, 1993; Jo et al., 1996; Steinitz et al., 2003), in which somatic embryos have
Preparation of plant material. Seeds of Habanero pepper (C. chinense Jacq.) cultivar BV11-03 were surface sterilized with a solution of ethanol at $70 \%$ for $5 \mathrm{~min}$, rinsed three times in sterile distilled water, soaked in a solution of commercial sodium hypochlorite at $30 \%$ for $15 \mathrm{~min}$, and rinsed again three times in sterile distilled water. After disinfection, the seeds were submerged in sterile distilled water for $24 \mathrm{~h}$. The zygotic embryos were extracted from the seeds by dissection and cotyledons were cut from the seeds immediately after the pretreatment in water, with the help of a stereomicroscope, tweezers, and a scalpel. To obtain the other types of explants, the sterile seeds were cultured in glass jars with $20 \mathrm{~mL}$ germination medium composed of mineral salts recommended by Murashige and Skoog (MS) (1962), supplemented with $\mathrm{GA}_{3} 1.1 \mu \mathrm{M}$, sucrose $3 \%$, and gelrite $0.2 \%$. The $\mathrm{pH}$ was adjusted to 5.6 before sterilization in autoclave. The cultures were incubated in darkness for $7 \mathrm{~d}$ to accelerate germination. After the seeds had germinated, they were transferred to a photoperiod 
of $16 \mathrm{~h}$ light $\left(40-50 \mu \mathrm{mol} \cdot \mathrm{m}^{-2} \cdot \mathrm{s}^{-1}\right)$ at $25 \pm 2$ ${ }^{\circ} \mathrm{C}$. The germinated zygotic embryos were extracted when the radicule became visible (7-8 d after planting in the germination medium), whereas the hypocotyls and cotyledonary leaves were extracted from the dissection of plantlets at $15 \mathrm{~d}$ of germination.

Induction of somatic embryogenesis. To induce somatic embryogenesis, different types of explants were cultured (cotyledons, zygotic embryos, germinated zygotic embryos, hypocotyls, and cotyledonary leaves) in different treatments. All the media contained the salts recommended by Murashige and Skoog (1962) and were always supplemented with sucrose $3 \%$, cisteine $\mathrm{HCl} 142.36 \mu \mathrm{M}$, myo-inositol 554.93 $\mu \mathrm{M}$, and thiamine $\mathrm{HCl} 29.64 \mu \mathrm{M}$. The media were solidified with gelrite $0.2 \%$ and the $\mathrm{pH}$ was adjusted to 5.8 before they were sterilized in autoclave $\left(121^{\circ} \mathrm{C}\right.$ for $\left.15 \mathrm{~min}\right)$. The cultures were incubated at $25 \pm 2{ }^{\circ} \mathrm{C}$ under photoperiod conditions (16 h light) and in darkness. Thirty explants per treatment were used and were evaluated over a period of 12 weeks.

Development of somatic embryos. Somatic embryos in globular and heart-shaped stages, obtained after 4 weeks of induction in the MS medium containing 9.05 $\mu \mathrm{M} 2,4-\mathrm{D}$ (T2), were transferred to different culture media (the same media that were evaluated during the induction step; Table 1) to evaluate the development of somatic embryos at more advanced stages (torpedo and cotyledonary). They were maintained in these media for 8 weeks, and changes were evaluated and recorded.

Pretreatment of somatic embryos with abscisic acid (ABA). The somatic embryos in torpedo and cotyledonary stages were transferred to solid and liquid culture media containing ABA $1.89 \mu \mathrm{m}$. In both media, only the concentration of the salts (MS/2) was modified. The embryos cultured in liquid medium were incubated in $250 \mathrm{~mL}$ Erlenmeyer flasks containing $50 \mathrm{~mL}$ medium at $80 \mathrm{~g}$. The somatic embryos in both the solid and the liquid media were incubated in darkness at $25 \pm 2{ }^{\circ} \mathrm{C}$ for $21 \mathrm{~d}$.

Germination of somatic embryos. After pretreatment with ABA, the somatic embryos were transferred to two germination media (solid and liquid media) composed of MS salts, $\mathrm{GA}_{3} 1.1 \mu \mathrm{M}$, and sucrose $3 \%$. For the solid media, gelrite $0.2 \%$ was added (Santana-Buzzy et al., 2005). The somatic embryos in liquid media were placed on a paper bridge. Both the solid and liquid media were incubated in photoperiod $(16 \mathrm{~h}$ light) at $25 \pm 2{ }^{\circ} \mathrm{C}$ for $15 \mathrm{~d}$.

\section{Results}

Induction and development of somatic embryogenesis. The results obtained (Table 1) show that, from the 21 culture media evaluated, only in two was it possible to induce the formation of somatic embryos: the T2 (MS + $9.05 \mu \mathrm{M} 2,4-\mathrm{D})$ and in the T17 $\left[\mathrm{MS}+9.05 \mu_{\mathrm{M}}\right.$ 2,4-D + $0.1 \mu_{\mathrm{M}}$ 2,4-epibrassi-

Table 1. Effect of different culture media on explants of Habanero pepper (Capsicum chinense Jacq.) in the formation of somatic embryos after $30 \mathrm{~d}$ of culture.

\begin{tabular}{|c|c|c|c|c|}
\hline \multirow[b]{2}{*}{ Culture media $(\mathrm{T})$} & \multicolumn{4}{|c|}{ Formation of somatic embryos } \\
\hline & $\overline{\mathrm{ZE}}$ & GZE & CL & HYP \\
\hline T0: Control MS & - & - & - & - \\
\hline $\mathrm{T} 1: \mathrm{MS}+2,4-\mathrm{D}(4.5 \mu \mathrm{M})$ & - & - & - & - \\
\hline $\mathrm{T} 2: \mathrm{MS}+2,4-\mathrm{D}(9.05 \mu \mathrm{M})$ & + & + & + & + \\
\hline T3: MS + ZEA $(4.5 \mu \mathrm{M})$ & - & - & - & - \\
\hline T4: MS + ZEA $(9.1 \mu \mathrm{M})$ & - & - & - & - \\
\hline T5: MS + BAP $(0.045 \mu \mathrm{M})$ & - & - & - & - \\
\hline T6: MS + BAP $(0.45 \mu \mathrm{M})$ & - & - & - & - \\
\hline T7: MS + BAP $(4.5 \mu \mathrm{M})$ & - & - & - & - \\
\hline T8: MS + KIN $(2.3 \mu \mathrm{M})$ & - & - & - & - \\
\hline T9: MS + EBR $(0.1 \mu \mathrm{M})$ & - & - & - & - \\
\hline T10: MS + TDZ $(2 \mu \mathrm{M})$ & - & - & - & - \\
\hline T11: MS + 2,4-D $(9.05 \mu \mathrm{M})+$ ZEA $(4.5 \mu \mathrm{M})$ & - & - & - & - \\
\hline T12: MS + 2,4-D (9.05 $\mu \mathrm{M})+$ ZEA $(9.1 \mu \mathrm{M})$ & - & - & - & - \\
\hline T13: MS + BAP $(0.045 \mu \mathrm{M})+2,4-\mathrm{D}(9.05 \mu \mathrm{M})$ & - & - & - & - \\
\hline T14: MS + BAP $(0.45 \mu \mathrm{M})+2,4-\mathrm{D}(9.05 \mu \mathrm{M})$ & - & - & - & - \\
\hline T15: MS + BAP $(4.5 \mu \mathrm{M})+2,4-\mathrm{D}(9.05 \mu \mathrm{M})$ & - & - & - & - \\
\hline T16: MS + KIN $\left(2.3 \mu_{\mathrm{M}}\right)+2,4-\mathrm{D}\left(9.05 \mu_{\mathrm{M}}\right)$ & - & - & - & - \\
\hline T17: MS + 2,4-D $(9.05 \mu \mathrm{M})+\mathrm{EBR}(0.1 \mu \mathrm{M})$ & + & + & + & + \\
\hline T18: MS + 2,4-D (9.05 $\mu \mathrm{M})+$ TDZ $(2 \mu \mathrm{M})$ & - & - & - & - \\
\hline T19: MS/2) + BAP $(0.045 \mu \mathrm{M})+2,4-\mathrm{D}(9.05 \mu \mathrm{M})$ & - & - & - & - \\
\hline T20: MS/2) + BAP $\left(0.45 \mu_{\mathrm{M}}\right)+2,4-\mathrm{D}\left(9.05 \mu_{\mathrm{M}}\right)$ & - & - & - & - \\
\hline T21: MS/2 + BAP $(4.5 \mu \mathrm{M})+2,4-\mathrm{D}(9.05 \mu \mathrm{M})$ & - & - & - & - \\
\hline
\end{tabular}

2,4-D, 2,4-dichlorophenoxyacetic acid; ABA, abscisic acid; BAP: 6-benzyladenine; CL, cotyledonary leaves; EBR: 2,4-epibrassinolide; GZE, germinated zygotic embryo; HYP, hypocotyls; KIN, kinetin; MS, Murashige and Skoog medium; TDZ, thiadiazuron; ZE, zygotic embryo; ZEA, zeatin.

nolide (EBR)] media. The formation of somatic embryos always occurred directly from the explant, and they were clearly visible from 30 to $45 \mathrm{~d}$ of induction in the $\mathrm{T} 2$ medium. However, the origin of the embryos varied depending on the explant source. When germinated zygotic embryos were used, somatic embryos began to appear around the area of the cut, and at the ends of the explants where greater proliferation was observed, and then spread over the surface of the explants (Fig. 1a). In cotyledonary leaves (Fig. 1b, c), cotyledons (Fig. 1d), and zygotic embryos (Fig. 1e, f), the embryos formed directly on the surface of the explant. When cotyledons were used as explants, the somatic embryos formed only from the damaged embryogenic tissue that resulted from the dissection of the seeds, proving to be the least adequate explant as a result of the lack of available tissue and the low frequency of somatic embryos formed, compared with the rest of the explants evaluated. That is the reason that evaluation of this explant did not continue in this study. When hypocotyls were used, the somatic embryos originated in the interior of the explant, probably from vascular tissue, and were only visible after the dermis of the explant was eliminated (Fig. 2a-c). The pronounced enlargement of the explant indicated that the process was taking place and, after the dermis was removed, the embryos in the globular stage began to multiply adventitiously (Fig. 2d, e). All the explants (zygotic embryos, germinated zygotic embryos, cotyledonary leaves, hypocotyls, and cotyledons) formed embryos in the T2 media. They showed a normal development pattern and morphology in accordance with the stages through which a somatic embryo must pass in dicotyledonous species (Fig. 3a-e).
In T17 medium, with the exception of cotyledonary leaves, in the rest of the explants evaluated deformed embryos were observed, which became pale brown and subsequently died. These results allow us to infer that the composition of the culture media appears to exert more influence on the induction of somatic embryogenesis in Habanero pepper than the type of explant, when the explants originate from aseptic plantlets (15-d-old). This behavior could probably vary considerably if the explants were from adult plants or were maintained in different culture conditions.

As can be observed in Fig. 4, during the induction of somatic embryogenesis, with the exception of zygotic embryos in which the response oscillated between $40 \%$ and $50 \%$ for both culture conditions (photoperiod and darkness respectively), the number of explants forming somatic embryos for the rest of the explants evaluated (germinated zygotic embryos, cotyledonary leaves, and hypocotyls) was superior to $80 \%$, both in photoperiod and in darkness, with no evidence of significant differences between the two culture conditions, although cotyledonary leaves and hypocotyls did show a slightly higher response when cultured in darkness $(100 \%)$. However, in an analysis of the number of somatic embryos formed (Fig. 4b), hypocotyls showed the greatest production $(175 \pm 20$ somatic embryos per explant) in photoperiod conditions, whereas in darkness, although $100 \%$ of the hypocotyl segments formed embryos (Fig. 4a), the number of embryos per explant did not exceed 35 to 40 somatic embryos per explant (Fig. 4b).

Although germinated zygotic embryos showed an average behavior in relation to the capacity of the explant to form embryos $(80 \pm 10$ somatic embryos per explant) and 

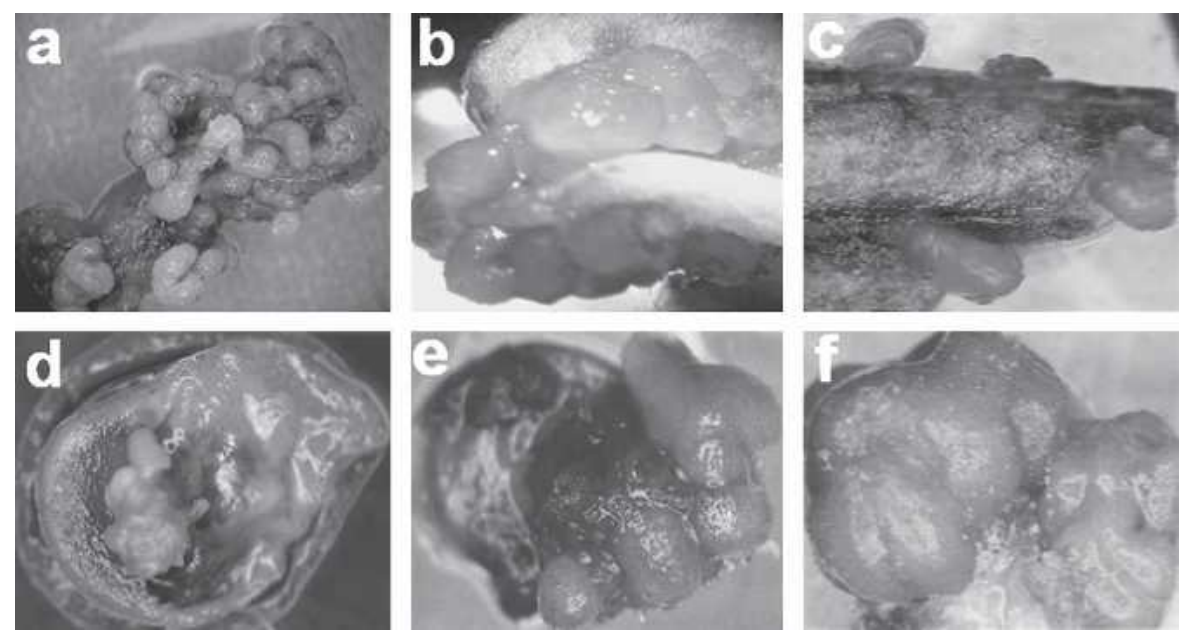

Fig. 1. Direct somatic embryogenesis obtained in the T2 medium (2,4-D 9.05 $\mu \mathrm{M})$ from different explants of Habanero pepper. (a) Somatic embryos in torpedo and cotyledonary stages, formed from germinated zygotic embryos (60 d culture in photoperiod). (b, c) Somatic embryos formed from cotyledonary leaves (45-d culture in photoperiod). (d) Somatic embryos formed from embryonic tissue of the cotyledons halved longitudinally (30-d culture in darkness). (e, f) Somatic embryos formed from zygotic embryos (45-d culture in darkness and photoperiod respectively).
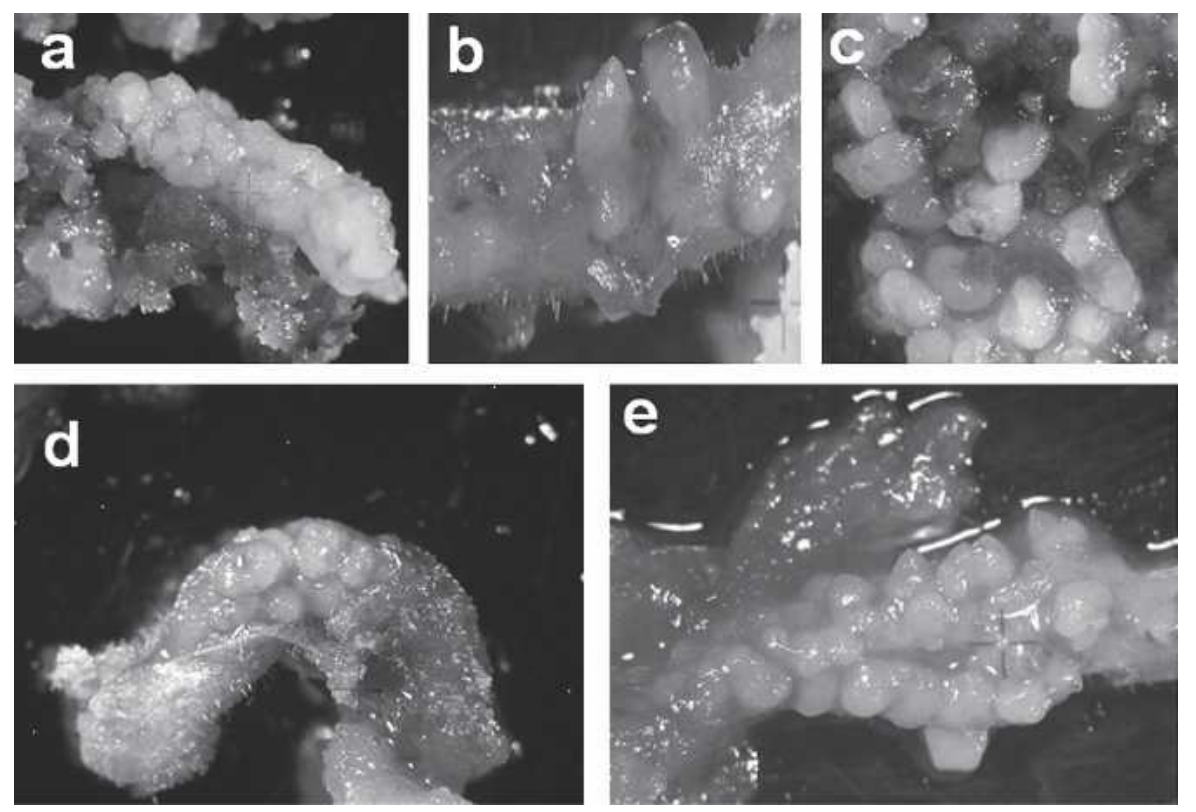

Fig. 2. Direct somatic embryogenesis of hypocotyl explants of the Habanero pepper obtained in the T2 medium (2,4-D $9.05 \mu \mathrm{M})$. (a) Somatic embryos in globular stage. (b) Somatic embryos in torpedo stage. (c) Somatic embryos without connection to original tissue. (d, e) Somatic embryos formed from the internal tissue of the explant. They became visible when the epidermis was eliminated. cotyledonary leaves formed $\approx 45$ to 55 somatic embryos per explant, both systems could also be appropriate options for use in the genetic transformation of this species, if they were the indicated explants. The results demonstrate that hypocotyls, germinated zygotic embryos, and cotyledonary leaves showed a considerable embryogenic capacity, as well as a high reproducibility of the process. The remainder of the explants differed significantly, both in photoperiod conditions and in darkness, with zygotic embryos being the explant that produced the smallest number of embryos per explant (Fig. 4b).

An analysis of the effect of photoperiod and darkness on the frequency of embryos formed per explant and the developmental stages of the embryos (globular, heart shaped, torpedo, and cotyledonary), at $45 \mathrm{~d}$ of induction in the T2 media (Fig. 5) demonstrated that culture under photoperiod conditions were the best for the induction and development of somatic embryogenesis, for all the explants evaluated, with hypocotyls being the explants with greater capacity of response.

In relation to the development of somatic embryos, the stages observed most frequently were globular and torpedo, particularly in photoperiod conditions. In general, the heartshaped stage registered a very low frequency, both in the different explants and for the different incubation conditions. Steinitz et al. (2003), working with $C$. annuum and using centrophenoxine as plant growth regulator, observed similar behavior: After the embryos in the globular stage became visible, they advanced progressively until they reached an elongated bipolar shape and eventually root and shoot poles, without the appearance of heart-shaped or torpedo stages, typical in somatic embryogenesis. Among other possible interpretations, this behavior could be attributed to the possibility that after the globular stage is reached, the transition from one stage to another during the histodifferentiation occurs very quickly or is almost imperceptible. Zygotic embryos proved to be the explants with the least capacity to form somatic embryos (10 somatic embryos per explant); however, when germinated zygotic embryos were used as an explant, they not only showed more frequency of formed embryos (87 somatic embryos per explant), but also the majority reached the torpedo
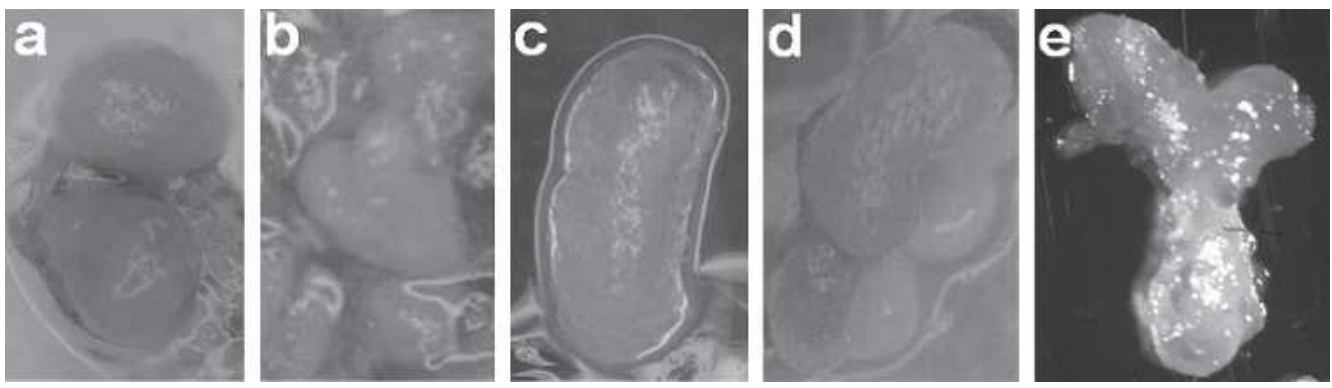

Fig. 3. Different shapes of somatic embryos of habanero pepper. (a) Globular. (b) Heart shaped. (c) Torpedo. (d) Cotyledonary in early stage. (e) Cotyledonary in late stage. 
$\mathbf{A}$

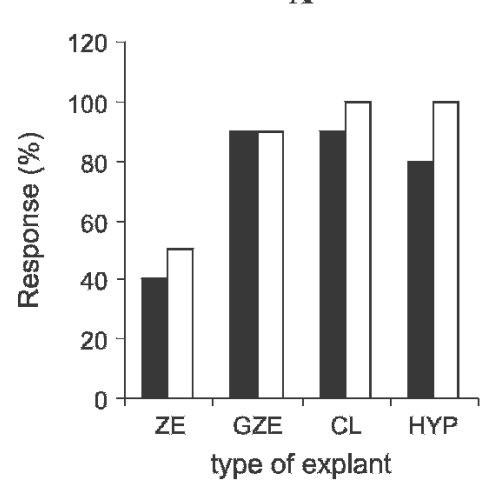

B

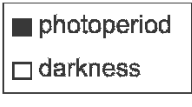

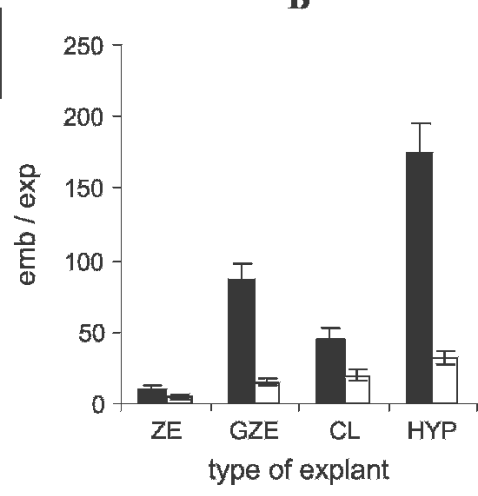

Fig. 4. (A) Response (percent) to somatic embryogenesis of the different explants of Habanero pepper evaluated. (B) Number of somatic embryos formed per explant. CL, cotyledonary leaves; GZE, germinated zygotic embryos; HYP, hypocotyl; ZE, zygotic embryo.

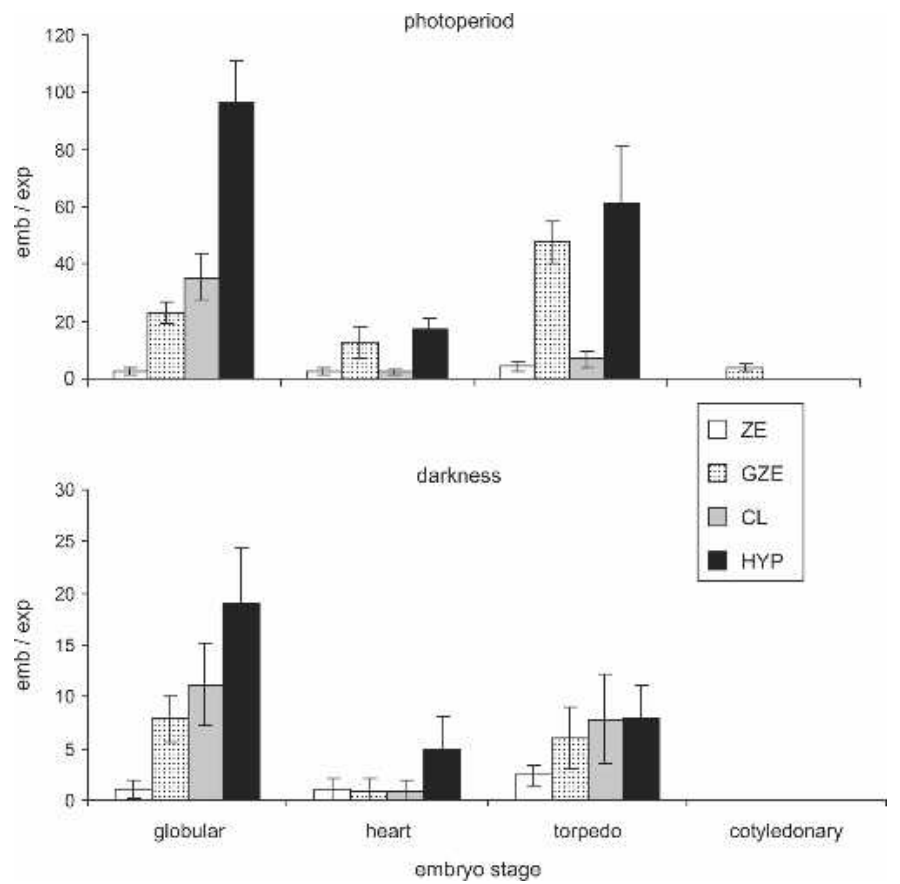

Fig. 5. Effect of culture conditions, photoperiod and darkness, on the frequency of formed embryos per explant and on the developmental stages of the embryos (globular, heart shaped, torpedo, and cotyledonary), at $45 \mathrm{~d}$ of induction in the $\mathrm{T} 2$ medium.
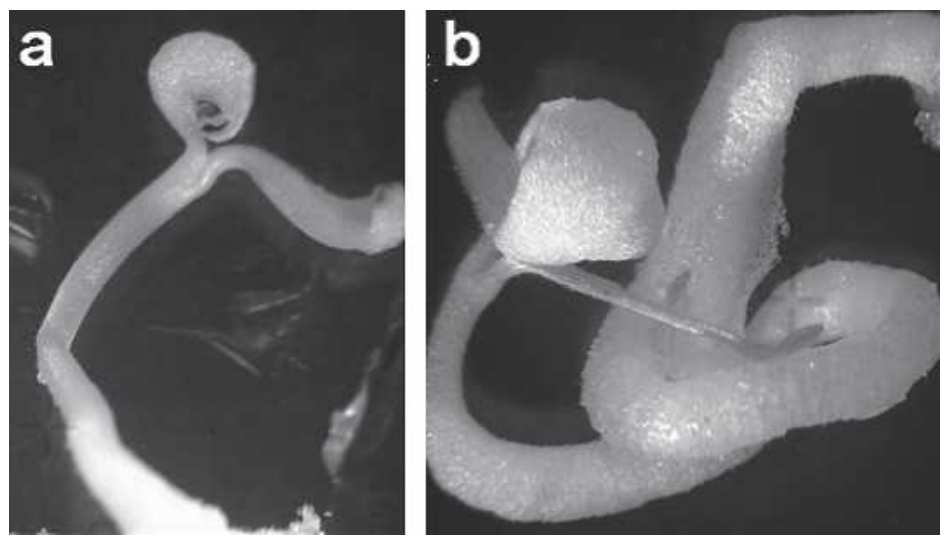

Fig. 6. Plantlets developed from somatic embryos of Capsicum chinense Jacq. in solid germination medium, Murashige and Skoog (MS) $+1.1 \mu \mathrm{MA}_{3}$. (a) From germinated zygotic embryo explant (showing cotyledonary leaves). (b) From cotyledonary leaves as explant (note the first pair of true leaves).

stage and only a few of them the reached the cotyledonary stage (Fig. 5)

Maturing and germination of somatic embryos. The somatic embryos induced and developed in the T2 medium MS + 2,4-D $(9.05 \mu \mathrm{M})$, and subcultured afterward in a liquid medium with $1.89 \mu \mathrm{M}$ ABA, showed a rapid elongation of the hypocotyl when transferred to the germination medium (1.1 $\mu \mathrm{M} \mathrm{GA}_{3}$; Fig. 6a). Their color changed to green and the majority $(60 \%)$ progressed to germination, as can be seen in Fig. 6b. However, although the embryos induced in the T2 medium, developed in the T21 medium $[\mathrm{MS} / 2+5 \mu \mathrm{M}$ 6-benzyladenine (BAP) + $9.05 \mu \mathrm{M} 2,4-\mathrm{D}]$, and pretreated with $\mathrm{ABA}$ (liquid medium) did germinate, there was a high frequency of fused embryos $(20 \%)$ (Fig. 7a,b). According to Steinitz et al. (2003), working with $C$. annuum, it was possible to observe a wide range of morphological abnormalities, such as the absence of cotyledons, development of a single deformed cotyledon, and a wine glass-shaped cotyledon, but the most critical defect was the absence of a normal and completely functional apical meristem in the embryo.

\section{Discussion}

One of the most relevant conclusions reached in this study is the capacity of the Habanero pepper ( $C$. chinense J.) to form somatic embryos contrary to the behavior reported for other species of the genus, particularly $C$. annuum, which to date has demonstrated and sustained the recalcitrance of the Capsicum genus to in vitro morphogenesis. The habanero pepper showed great plasticity and capacity to produce somatic embryos, regardless of the explant used, and despite belonging to the Capsicum genus, which is known for its low capacity of in vitro plant regeneration. In our study, all the explants evaluated were capable of forming somatic embryos in the same culture media: zygotic embryos and germinated zygotic embryos; cotyledonary leaves, cotyledons, and hypocotyls. Germinated zygotic embryos and hypocotyls explants registered the greatest frequencies of somatic embryo formation (87 somatic embryos per explant and 175 somatic embryos per explant respectively), taking into account that it is direct somatic embryogenesis. Although cotyledonary leaves showed less frequency of formed embryos (45 somatic embryos per explant), compared with germinated zygotic embryos and hypocotyls, these were the embryos that reached germination in greater number. Zygotic embryos and cotyledons, with 10 and 5 somatic embryos per explant respectively, registered the smallest number of formed embryos. The somatic embryos formed from hypocotyls only emerged or became visible when the epidermis of the explant was removed; they never formed on the surface, probably because their embryogenic capacity is confined to the vascular cells of the plant. 

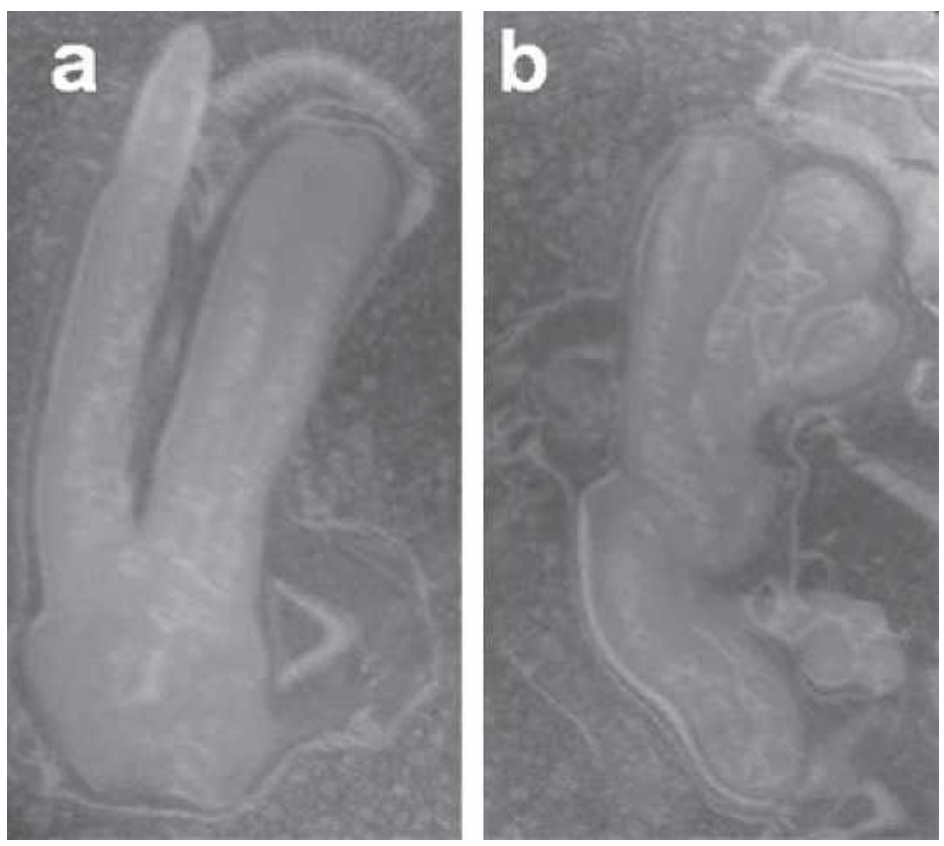

Fig. 7. Fused somatic embryos (FSE). Abnormality frequently observed when the somatic embryos of Habanero pepper previously treated with abscisic acid in liquid medium, were subcultured in the T21 medium (MS/2 + $5 \mu_{\mathrm{M}}$ 6-benzyladenine + $9.05 \mu_{\mathrm{M}}$ 2,4-D) for their development. (a) FSE with poor cotyledonary leaf development and wide degeneration of root area. (b) FSE with abnormal cotyledons.

In this study, somatic embryogenesis was induced, exceptionally, in all the types of explants evaluated and in the same culture media (T2). These results are in marked contrast to some reports referring to C. annuum for two basic reasons. The first is that the majority of established protocols are limited to the use of the zygotic embryo, mature or immature, as the initial explant (Binzel et al., 1996; Buyukalaca and Mavituna, 1996; Harini and Sita, 1993; Jo et al., 1996; Steinitz et al., 2003). Only Kintzios et al. (2001) reported the formation of somatic embryos from mature leaves of $C$. annuum, and, with the exception of Buyukalaca and Mavituna (1996), who obtained somatic embryos from cells in suspension, in all the other reports of indirect somatic embryogenesis (Jo et al., 1996; Kintzios et al., 2001), the somatic embryos were induced from callus in solid media. The second reason is that most reports agree that somatic embryogenesis was controlled by the 2,4-D combined with thidiazuron (Binzel et al., 1996), coconut water (Harini and Sita, 1993; Binzel et al., 1996), or BAP (Kintzios et al., 2001). Our results showed that during the entire development of somatic embryogenesis of habanero pepper, the presence of 2,4-D was determinative. Similar results were reported by Buyukalaca and Mavituna (1996) and Jo et al. (1996), whereas Steinitz et al. (2003) managed to induce somatic embryos in 12 genotypes of C. annuum using either 2,4-D or centrophenoxine, with the greatest number of embryos per explant being obtained with the latter.

Compared with other reports of direct somatic embryogenesis carried out in the Capsicum genus to date, Harini and Sita (1993) obtained 6 to 19 somatic embryos per explant; Binzel et al. (1996) obtained six somatic embryos per explant, both from immature zygotic embryos. Steinitz et al. (2003) obtained six somatic embryos per explant when mature somatic embryos were used. With our protocol, it was possible to achieve a greater number of formed somatic embryos per explant (175 \pm 20 from hypocotyls). However, in this study, after the cotyledonary stage was reached, germination and conversion to plants was not equally successful. Many of the embryos did not germinate, many others germinated but did not manage to convert to plants, and, on very few occasions, in some treatments, different abnormalities in the morphology of the somatic embryo were observed. In general, very frequently, after somatic embryogenesis is induced, many of the globular somatic embryos that are formed do not progress to more advanced stages, or many of the embryos that reach the torpedo and cotyledonary stages show a wide range of malformations. It was possible to observe that when 2,4-D was combined with EBR or BAP, fused somatic embryos were frequently generated. The same phenomenon was reported by Rodríguez and Wetzstein (1994), Carraway and Merkle (1997), Benelli et al. (2001), Stipp et al. (2001), and Tomaz et al. (2001). Although the causes provoking these disorders in the normal development of the embryos are still imprecise and unpredictable, it is likely that the prolonged exposure of the somatic embryos to $2,4-\mathrm{D}$, particularly during histodifferentiation, could induce this type of behavior. Some reports have revealed that exogenous auxins stimulate the polarization of proembryogenic cells, but inhibit the subsequent development of the somatic embryo (Michalczuk et al., 1992a, b; Schiavone and Cooke, 1987). Thus, for the transition of the somatic embryo from the globular stage to the more advanced stages, the exogenous auxins must be removed, so that the gene involved in the expression of the stages, during the development of the somatic embryos can be activated (Zimmerman, 1993). The presence of abnormalities observed in the somatic embryos of chili has also been described in other species (Ammirato, 1987; Merkle et al., 1995), and the concurrence of normal and abnormal embryos in the same culture is very common. Besides fused embryos, other types of abnormalities have been reported, such as the absence of cotyledons, a single cotyledon or malformed cotyledons (Carraway and Merkle, 1997, Jayasankar et al., 2002), lack of a shoot, or anomalies in apical meristem histodifferentiation (Jayasankar et al., 2002; Stipp et al., 2001; Suhasini et al., 1996). Binzel et al. (1996) observed abnormal somatic embryos of chili that, together with normal embryos, also became plants. However, in this work, the fused embryos did not develop into a plant, which coincides with the report by Steinitz et al. (2003) on C. annuum.

We have established the first and most promising system for direct somatic embryogenesis in a recalcitrant species, $C$. chinense, using hypocotyl explants. Fortunately, the advances we have made show that the production of somatic embryos in this species can be efficient and reproducible, at least up to the point when the somatic embryo reaches the torpedo and cotyledonary stages. This surpasses reports carried out for other species of the Capsicum genus. However, further research on the germination and conversion to plants will be necessary. It is evident that the use of ABA influenced the maturing of the embryos, because only those treated with this regulator before germination were able to develop their cotyledonary leaves. Nevertheless, this is one of the factors that must be considered to optimize the somatic embryogenesis of habanero pepper. $\mathrm{ABA}$ has been used successfully in several studies of somatic embryogenesis. It is considered to be an inhibitor of early germination of the embryos and, for some species, it can be critical for the conversion of embryos to plants (Ammirato, 1983; Redenbaugh et al., 1991). In C. annuum, it was used successfully by Buyukalaca and Mavituna (1996) and Jo et al. (1996).

Genetic improvement of habanero pepper cultivars for disease and insect pest resistance, among other characters, can be achieved efficiently through genetic engineering. To date, difficulties in regeneration via somatic embryogenesis and organogenesis, in particular shoot elongation from induced adventitious shoot buds, and nonreproducibility of results in tissue cultures of the Capsicum genus, have restricted work on genetic transformation (Peddaboina et al., 2003); however, the protocol we have established could prove to be attractive, not only for genetic transformation, but also for many other types of research relating to the different stresses affecting the cultivation of habanero pepper. 


\section{Literature Cited}

Ammirato, P.V. 1983. Embryogenesis, p. 82-113. In: D.A. Evans, W.R. Sharp, P.V. Ammirato, and Y. Yamada (eds.). Handbook of plant cell culture. Vol. 1. MacMillan, New York.

Ammirato, P.V. 1987. Organizational events during somatic embryogenesis, p. 57-81. In: C.E. Green, D.A. Somers, W.P. Hackett, D.D. Biesboer (eds.). Plant tissue and cell culture. Liss, New York.

Benelli, C., A. Fabbri, S. Grassi, M. Lambardi, and E. Rugini. 2001. Histology of somatic embryogenesis in mature tissue of olive (Olea europaea L.). J. Hort. Sci. Biotechnol. 76:112-119.

Binzel, M.L., N. Sankhla, S. Joshi, and D. Sankhla. 1996. Induction of direct somatic embryogenesis and plant regeneration in pepper (Capsicum annuum L.). Plant Cell Rep. 15:536-540.

Buyukalaca, S. and F. Mavituna. 1996. Somatic embryogenesis and plant regeneration of pepper in liquid media. Plant Cell Tiss. Org. Cult 46:227-235.

Carraway, D.T. and S.A. Merkle. 1997. Plantlet regeneration from somatic embryos of American chestnut. Can. J. For. Res. 27:1805-1812.

DeWitt, D. and P.W. Bosland. 1993. The pepper garden. Ten Speed Press, Berkeley, Calif.

Franck-Duchenne, M., Y. Wang, S. Ben Tahar, and R.N. Beachy. 1998. In vitro stem elongation of sweet pepper in media containing 2,4-epibrassinolide. Plant Cell Tiss. Org. Cult. 53:79-84.

Greenleaf, W.H. 1986. Pepper breeding. In: M.J. Bassett (ed.). Breeding vegetable crops. AVI Publishing, Westport, Conn, p. 67-134.

Harini, I. and G.L. Sita. 1993. Direct somatic embryogenesis and plant regeneration from immature embryos of chili (Capsicum annuum L.). Plant Sci. 89:107-112.

Jayasankar, S., B.R. Bondada, Z. Li, and D.J. Gray. 2002. A unique morphotype of grapevine somatic embryos exhibits accelerated germination and early plant development. Plant Cell Rep. 20:907-911.
Jo, J.-Y., E.-Y. Choi, D. Choi, and K.-W. Lee. 1996. Somatic embryogenesis and plant regeneration from immature zygotic embryo culture in pepper (Capsicum annuum L.). J. Plant. Biol. 39:127-135.

Kintzios, S., J.B. Drossopolous, and C. Lymperopoulos. 2001. Effect of vitamins and inorganic micronutrients on callus growth and somatic embryogenesis from leaves of chili pepper. Plant Cell Tiss. Org. Cult. 67:55-62.

Maheswaran, G. and E.G. Williams. 1984. Direct somatic embryoid formation on immature embryos of Trifolium repens, $T$. pratense and Medicago sativa, and rapid clonal propagation. Ann. Bot. (Lond.) 54:201-212.

Merkle, S.A., W.A. Parrott, and B.S. Flinn. 1995. Morphogenic aspects of somatic embryogenesis, p. 155-203. In: T.A. Thorpe (ed.). In vitro embryogenesis in plants. Kluwer Academic Publishers, Dordrecht, The Netherlands.

Michalczuk, L., T.J. Cooke, and J.D. Cohen. 1992a. Auxin levels at different stages of carrot somatic embryogenesis. Phytochemistry 31:1097-1103.

Michalczuk, L., D.M. Ribnicky, T.J. Cooke, and J.D. Cohen. 1992b. Regulation of indole-3acetic acid biosynthetic pathways in carrot cell cultures. Plant Physiol. 100:1346-1353.

Murashige, T. and F. Skoog. 1962. A revised medium for rapid growth and bioassay with tobacco tissue culture. Physiol. Plant. 15:473-497.

Peddaboina, V., C. Thamidala, and S. Karampuri. 2003. Thidiazuron induced high frequency adventitious shoot formation and plant regeneration in Capsicum annuum L. J. Plant Biotech 5:245-250.

Redenbaugh, K., J. Fujii, D. Slade, P. Viss, and M. Kossler. 1991. Artificial seeds: Encapsulated somatic embryos, p. 395-416. In: Y.P.S. Bajaj (ed.). Biotechnology in agriculture and forestry. Vol. 17. Springer-Verlag, Berlin.

Rodríguez, A.P.M. and H.Y. Wetzstein. 1994. The effect of auxin type and concentration on pecan
(Carya illinoinensis) somatic embryo morphology and subsequent conversion into plants Plant Cell Rep. 13:607-611.

Santana-Buzzy, N., A. Canto-Flick, F. BarahonaPérez, M.C. Montalvo-Peniche, P.Y. ZapataCastillo, A. Solís-Ruíz, A. Zaldívar-Collí, O. Gutiérrez-Alonso, and M.L. Miranda-Ham. 2005. Regeneration of Habanero pepper ( $\mathrm{Cap}$ sicum chinense Jacq.) via organogenesis. HortScience 40:1829-1831.

Santana-Buzzy, N., A. Canto-Flick, L.G. IglesiasAndreu, M.C. Montalvo-Peniche, G. LópezPuc, and F. Barahona-Pérez. 2006. Improvement of in vitro culturing of Habanero pepper by inhibition of ethylene effects. HortScience 41:405-409.

Schiavone, F.M. and T.J. Cooke. 1987. Unusual patterns of somatic embryogenesis in the domesticated carrot: Developmental effects of exogenous auxins and auxin transport inhibitors. Cell Differ. 21:53-62.

Steinitz, B., M. Küsek, Y. Tabib, I. Paran, and A. Zelcer. 2003. Pepper (Capsicum annuum L.) regenerants obtained by direct somatic embryogenesis fail to develop a shoot. In Vitro Cell Dev. Biol. Plant 39:296-303.

Stipp, L.C.L., B.M.J. Mendes, S.M.D.S. Piedade, and A.P.M. Rodriguez. 2001. In vitro morphogenesis of Cucumis melo var. inodorus. Plant Cell Tiss. Org. Cult. 65:81-89.

Suhasini, K., A.P. Sagare and K.V. Krishnamurthy. 1996. Study of aberrant morphologies and lack of conversion of somatic embryos of chickpea (Cicer arietinum L.). In Vitro Cell. Dev. Biol. Plant 32:6-10.

Tomaz, M.L., B.M.J. Mendes, F. Filho, A.A.M De, C.G.B. Demetrio, N. Jansakul, and A.P.M. Rodriguez. 2001. Somatic embryogenesis in Citrus spp.: Carbohydrate stimulation and histodifferentiation. In Vitro Cell. Dev. Biol. Plant 37:446-452.

Zimmerman, J.L. 1993. Somatic embryogenesis: A model for early development in higher plants. Plant Cell 5:1411-1423. 